\title{
PENENTUAN KEJADIAN EL-NINO DAN LA-NINA BERDASARKAN NILAI SOUTHERN OSCILATION INDEKS
}

Heni Maulidiya ${ }^{1)}$, Andi Ihwan, M.Si 1) , Muh. Ishak Jumarang, M.Si 1)

1) Prodi Fisika FMIPA UNTAN

Email : lidiya1788@yahoo.co.id

\begin{abstract}
Abstrak
Telah dilakukan penelitian mengenai prediksi kejadian El-Nino dan La-Nina, berdasarkan nilai tekanan udara di Tahiti dan Darwin (nilai SOI) menggunakan Metode ARIMA. Data yang digunakan dalam penelitian ini adalah berupa data tekanan udara di Tahiti dan tekanan udara di Darwin selama 12 tahun mulai dari tahun 2000-2011. Hasil simulasi diperoleh, model yang paling cocok digunakan untuk prediksi tekanan udara Tahiti adalah $(1,2,0)(0,2,2)^{12}$ dan Darwin adalah $(1,2,2)(0,2,1)^{12}$. Model tekanan udara di Tahiti dan Darwin tersebut kemudian digunakan untuk memprediksi kejadian El-Nino dan La-Nina pada tahun 2012, yang dapat menunjukkan bahwa pada tahun 2012 terjadi El-Nino lemah sampai sedang, hal ini dapat mengakibatkan penurunan tingkat curah hujan di sebagian besar wilayah Indonesia.
\end{abstract}

Kata Kunci: Tekanan udara, El-Nino, La-Nina, SOI, dan ARIMA

\section{Pendahuluan}

Di wilayah tropis, seperti Indonesia, hujan menjadi kondisi yang dapat dijumpai sehari-hari terutama pada musim penghujan. Awal musim penghujan di wilayah Indonesia dari waktu ke waktu tidaklah sama persis. Perubahan awal musim dapat mengakibatkan aktivitas manusia terganggu. Contohnya pada bidang pertanian, yang dapat mengganggu produktivitas pertanian, bahkan dapat mengakibatkan gagal panen dan sebagainya.

Perubahan awal musim ini dapat disebut dengan anomali alam, contohnya yang berkaitan dengan iklim adalah fenomena alam El-Nino dan La-Nina. Kejadian El-Nino biasanya diikuti dengan penurunan curah hujan dan peninggkatan suhu udara, sedangkan kejadian La-Nina merangsang kenaikan curah hujan di atas curah hujan normal. Penentuan kejadian ElNino dan La-nina, salah satunya dapat dilihat berdasarkan dari data Southern Oscilation Indeks (SOI). Nilai SOI ini dapat diperoleh berdasarkan dari nilai tekanan udara di Tahiti dan di Darwin. Ada beberapa model yang dapat digunakan untuk memodelkan data time series seperti tekanan udara ini, salah satunya adalah metode Autoregresif Integrated Moving Average (ARIMA). Metode ARIMA merupakan metode yang dalam pengolahannya memanfaatkan data masa lalu dan masa sekarang untuk menghasilkan peramalan jangka pendek yang akurat.

Berdasarkan uraian di atas, maka dalam makalah ini akan dikaji lebih lanjut tentang kejadian-kejadian El-Nino dan La-Nina berdasarkan nilai SOI.

\section{Landasan Teori}

\subsection{Southern Oscilation Indeks (SOI)}

Walker menemukan adanya suatu hubungan antara osilasi curah hujan dan osilasi medan tekanan udara di selatan Ekuator yang kemudian dikenal dengan "Sel Walker" atau Osilasi Selatan. Osilasi Selatan adalah suatu osilasi yang tidak teratur, interannual dan berskala global, yang merupakan pertukaran massa udara antara daerah pusat tekanan rendah di Pasifik Barat sekitar ekuator yaitu daerah Indonesia-Australia (Indo-Australia), dengan pusat tekanan tinggi di Pasifik Tengah.

Indeks SOI ini secara sederhana merupakan perbedaan tekanan udara permukaan di daerah Pasifik Timur yang diukur di Tahiti, dengan tekanan udara permukaan di daerah Pasifik Barat (Indo-Australia) yang diukur di Darwin, Australia (Haryanto, 1998).

Pergeseran sirkulasi walker menyebabkan terjadinya udara subsiden di Indonesia (udara jatuh/turun, padahal seharusnya naik keatas akibat pemanasan di Ekuator). Apabila muson yang terjadi lemah akibat gradien tekanan udara selatan yang sangat kecil, aktivitas awan konveksi di khatulistiwa Indonesia berkurang (rendah) yang menyebabkan terjadinya El-Nino, musim kemarau berkepanjangan di Indonesia (Murtianto, 2012).

El-Nino dicirikan dengan melemahnya angin pasat dalam skala yang luas dan meningkatnya suhu permukaan air laut di Pasifik tengah dan Timur dekat ekuator. Selama berlangsungnya El-Nino, terjadi hal yang tidak biasa pada tekanan udara permukaaan pada samudra Pasifik. Di Pasifik Barat dan Samudra Hindia terbentuk pusat tekanan tinggi, sedangkan pada Pasifik Tengah dan Selatan 
terbentuk pusat tekanan rendah, sehingga SOI bernilai negatif (Haryanto, 1998).

Pada saat terjadi La-Nina angin pasat timur yang bertiup di sepanjang Samudra Pasifik menguat (Sirkulasi Walker bergeser ke arah Barat), sehingga massa air hangat yang terbawa semakin banyak ke arah Pasifik Barat, akibatnya massa air dingin di Pasifik Timur bergerak ke atas dan menggantikan massa air hangat yang berpindah tersebut, hal ini biasa disebut upwelling. Dengan pergantian massa air itulah suhu permukaan laut mengalami penurunan dari nilai normalnya, (Edukasi, 2010). Tekanan udara di kawasan equator Pasifik barat menurun, lebih ke barat dari keadaan normal, menyebabkan pembentukkan awan yang lebih dan hujan lebat di daerah sekitarnya (Haryanto, 1998).

Bila tekanan udara di Pasifik Barat cenderung menguat maka di Pasifik Timur dan Tengah cenderung melemah sehingga SOI bernilai negatif. Sebaliknya bila tekanan udara di Pasifik Barat cenderung melemah maka di Pasifik Timur dan Tengah cenderung menguat sehingga SOI bernilai positif. Adapun persamaan untuk menentukan nilai SOI adalah : (Haryanto, 1998).

$S O I=\frac{(\text { Pdiff }- \text { Pdiffav })}{S D} \times 10$

dengan :

Pdiff = Selisih SLP Tahiti dengan Darwin

Pdiffav = Rata-rata jangka panjang Pdiff di bulan tersebut

$\mathrm{SD} \quad=$ Standar Deviasi dari Pdiff

SOI = Southern Oscilation Indeks

SD = Standar Deviasi Bulanan dari Pdiff

Tahun kejadian El-Nino dan La-Nina ditentukan berdasarkan banyaknya kemunculan SOI yang nilainya signifikan (lebih besar dari +5 atau lebih kecil dari -5 ). Jika SOI lebih dari +5 berlangsung selama paling kurang enam bulan maka tahun bersangkutan dinyatakan sebagai tahun El-Nino, sedangkan jika SOI di antara -5 dan +5 maka dinyatakan sebagai tahun normal (Haryanto, 1998).

Tabel 2.1 Panduan prediksi El-Nino, La-Nina, atau normal terhadap nilai SOI

\begin{tabular}{ll}
\hline \multicolumn{2}{c}{ atau normal terhadap nilai SOI } \\
Nilai SOI & $\begin{array}{l}\text { Fenomena Yang } \\
\text { Akan Terjadi }\end{array}$ \\
\hline Dibawah -10 selama & \\
6 bulan & El-Nino kuat \\
-5 s/d -10 selama 6 & El-Nino lemah \\
bulan & sampai sedang \\
$-5 \mathrm{~s} / \mathrm{d}+5$ selama 6 & \\
bulan & Normal \\
$+5 \mathrm{~s} / \mathrm{d}+10$ selama 6 & La-Nina lemah \\
bulan & sampai sedang
\end{tabular}

Diatas +10 selama 6

$\frac{\text { bulan }}{\text { (Sumber : Gunawan, 2007) }}$

\subsection{Metode ARIMA}

Metode ARIMA merupakan metode yang dikembangkan oleh George Box dan Gwilym Jenkins sehingga nama mereka sering disinonimkan dengan proses ARIMA yang diterapkan untuk analisis data dan prediksi data runtun waktu.

ARIMA sering juga disebut metode runtun waktu Box-Jenkins. Model ARIMA adalah model yang secara penuh mengabaikan variabel bebas dalam membuat peramalan. ARIMA menggunakan nilai masa lalu dan sekarang dari variabel terikat untuk menghasilkan peramalan jangka pendek yang akurat. Secara umum model ARIMA dirumuskan dengan notasi ARIMA $(p, d, q)$ dalam hal ini :

$\mathrm{p}=$ Orde atau derajat autokolerasi (AR)

$\mathrm{d}=$ Orde atau derajat pembeda

$\mathrm{q}=$ Orde atau derajat $(\mathrm{MA})$

Model ARIMA secara musiman umumnya dinotasikan sebagai berikut: ARIMA $(p, d, q)(P, D, Q)^{\mathrm{s}}$. Dalam hal ini :

$(p, d, q)=$ Bagian yang tidak musiman dari model

$(P, D, Q)=$ Bagian musiman dari model

$s \quad=$ Jumlah periode musiman

Model AR dan MA dikombinasikan untuk menghasilkan model ARIMA dengan bentuk umum sebagai berikut :

$$
\begin{aligned}
Y_{t}= & \emptyset_{0}+\emptyset_{1} Y_{t-1}+\cdots+\emptyset_{p} Y_{t-p}+W_{1} \varepsilon_{t-1}- \\
& W_{2} \varepsilon_{t-2}-\cdots-W_{q} \varepsilon_{t-q}+\varepsilon_{t}
\end{aligned}
$$

\subsection{Tahapan Metode ARIMA \\ 2.3.1 Plot Time Series}

Langkah pertama yang baik untuk menganalisis data deret berkala (time series) adalah dengan memplot data asli tersebut secara grafis. Ini merupakan salah satu cara untuk menganalisis data deret berkala yaitu dengan menguraikan data tersebut ke dalam himpunan gelombang sinus (siklus) pada frekuensi yang berbeda. Apabila tersedia program untuk memplot data di komputer, maka akan sangat bermanfaat dalam memplot data tersebut.

\subsubsection{Kestasioneran Data}

Data dikatakan stasioner apabila data tersebut berada pada kisaran rata-rata yang sama sepanjang waktu. Plot autokorelasi dapat dengan mudah memperlihatkan ketidakstasioneran data. Stasioneritas yang berarti bahwa tidak terdapat pertumbuhan atau 
penurunan pada data. Dengan kata lain, fluktuasi data berada disekitar suatu nilai ratarata yang konstan sepanjang waktu. Apabila data yang diinput tidak stasioner, maka perlu dilakukan metode pembedaan (differencing), agar data tersebut menghasilkan data yang stasioner. Pembedaan tersebut dilakukan dengan cara mengurangi nilai data pada suatu periode dengan nilai periode sebelumnya. Dalam hal ini, metode pembedaan merupakan suatu alternatif yaitu prosedur yang penghitungannya lebih efisien dan lebih cocok untuk model-model ARIMA.

\subsubsection{Identifikasi Model}

Pada tahap ini merupakan penentuan model yang akan digunakan untuk prediksi yang dianggap paling sesuai. Sesudah memplot data deret berkala untuk pemeriksaan stasioneritas, maka selanjutnya adalah membuat grafik fungsi autokorelasi (FAK) dan fungsi Autokorelasi Parsial (FAKP). FAK digunakan untuk menentukan kestasioneran data runtun waktu, jika dari FAK data asli ternyata data belum stasioner, maka dilakukan penghalusan data, yaitu dengan cara mencari derajat selisih dari data asli, dapat menggunakan derajat selisih satu atau dua. FAKP digunakan untuk menentukan model dari data tersebut. Untuk menentukan model dari data tersebut dapat dilakukan dengan melihat pada lag berapa fungsi terputus. Jika data terlihat sudah stasioner maka sudah dapat diperkirakan model awalnya.

\subsubsection{Estimasi dan Verifikasi Parameter Model Sementara}

Setelah melakukan identifikasi, maka selanjutnya mencari nilai estimasi dari model yang sudah diperoleh tersebut untuk selanjutnya dilakukan prediksi. Estimasi awal yang diperoleh dalam langkah identifikasi dapat digunakan sebagai nilai awal dalam metode estimasi secara iteratif. Selanjutnya dilakukan uji statistik untuk verifikasi apakah model yang telah diestimasi itu cocok. Uji statistik ini dilakukan, untuk menunjukkan apakah model harus diubah kembali sampai akhirnya diperoleh model yang sangat cocok dan dapat digunakan untuk prediksi.

\subsubsection{Prediksi (Peramalan)}

Prediksi adalah suatu kegiatan untuk memperkirakan apa yang akan terjadi dimasa yang akan datang berdasarkan pada nilai-nilai yang diketahui. Dalam hal ini, prediksi diperlukan untuk melihat kapan suatu peristiwa akan terjadi, sehingga tindakan yang tepat dapat diambil. Untuk menentukan prediksi tekanan udara bulanan tahun 2011-2012 dengan metode runtun waktu (Makridakis, 1999).

\section{Metodologi}

Penelitian ini dilaksanakan di Laboratorium Komputasi Fisika FMIPA, UNTAN, mulai dari bulan Desember 2011 sampai dengan September 2012. Penelitian ini dilakukan dengan tahapan-tahapan studi pustaka, pengumpulan data, dan pengolahan data. Data yang digunakan berupa data sekunder, terdiri dari data tekanan udara Tahiti dan Darwin, serta data SOI dari tahun 2000-2011. Selain itu data kejadian El-Nino, La-Nina dan tahun normal. Data ini diperoleh dari Bureu Of Meteorology (BOM) dengan website http:// www.bom.gov. au/ climate/enso/enlist.

Adapun langkah-langkah dalam penentuan kejadian El-Nino dan La-Nina adalah sebagai berikut :

1. Dilakukan estimasi tekanan udara di Tahiti dan Darwin selama 12 Tahun (2000-2011), berdasarkan metode ARIMA.

2. Fungsi matematika yang diperoleh dari estimasi pada langkah pertama digunakan untuk memprediksi tekanan udara di Tahiti dan Darwin selama 2 tahun (2011-2012).

3. Hasil prediksi model di validasi dengan data observasi berdasarkan tingkat korelasinya.

4. Nilai SOI dihitung dari hasil prediksi tekanan udara Tahiti dan Darwin berdasarkan persamaan (2.1).

5. Divalidasi nilai SOI hasil prediksi dengan SOI observasi. Jika, nilai SOI antara keduanya terdapat kemiripan, maka hasil dianggap baik.

6. Dilakukan analisis kejadian El-Nino dan LaNina dari hasil prediksi tersebut.

\section{Hasil dan Diskusi}

Pada penelitian ini dilakukan prediksi kejadian-kejadian El-Nino dan La-Nina berdasarkan dari nilai SOI, selama 12 tahun mulai dari tahun 2000-2011 yang dapat dilihat pada Lampiran 1. Prediksi dilakukan dengan menggunakan metode statistik ARIMA dari data tekanan udara di Tahiti dan Darwin.

\subsection{Kestasioneran Data}

\subsubsection{Tekanan Udara Tahiti}

Pada penelitian ini, untuk memprediksi nilai tekanan udara dengan metode ARIMA, data time series harus bersifat stasioner, jika nilai tekanan udara yang dihasilkan memperlihatkan bahwa plot time series tidak stasioner, maka data harus di stasionerkan terlebih dahulu. Untuk mengetahui kestasioneran dari data tersebut, dapat dilihat berdasarkan grafik trend analisis seperti gambar (4.1). 


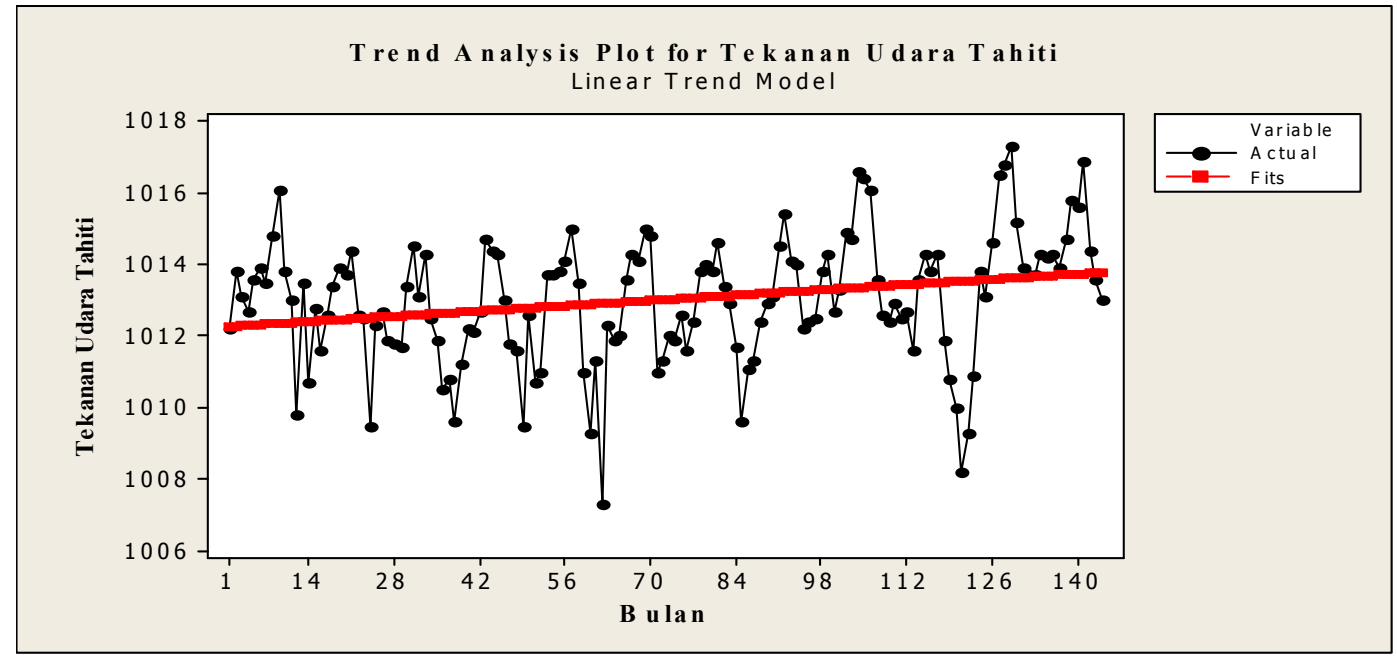

Gambar 4.1 Pola Trend Analisis Tekanan Udara Tahiti (144 Bulan)

Berdasarkan pada Gambar 4.1, bahwa pola trend dari data tersebut yang tidak mengikuti rata-ratanya, maka data dikatakan tidak stasioner. Oleh karena itu, agar data terlihat stasioner perlu dilakukan pembedaan (difference).

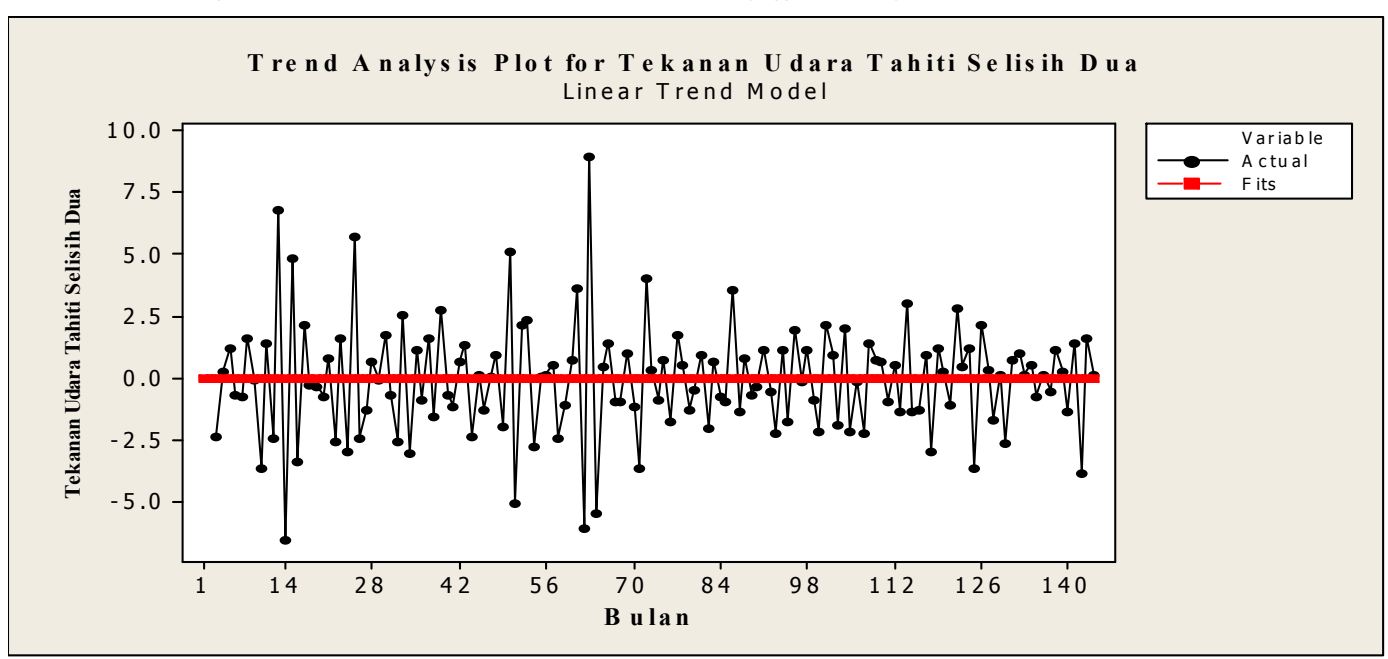

Gambar 4.2 Pola Trend Analisis Tekanan Udara Tahiti Setelah Differencing Dua kali

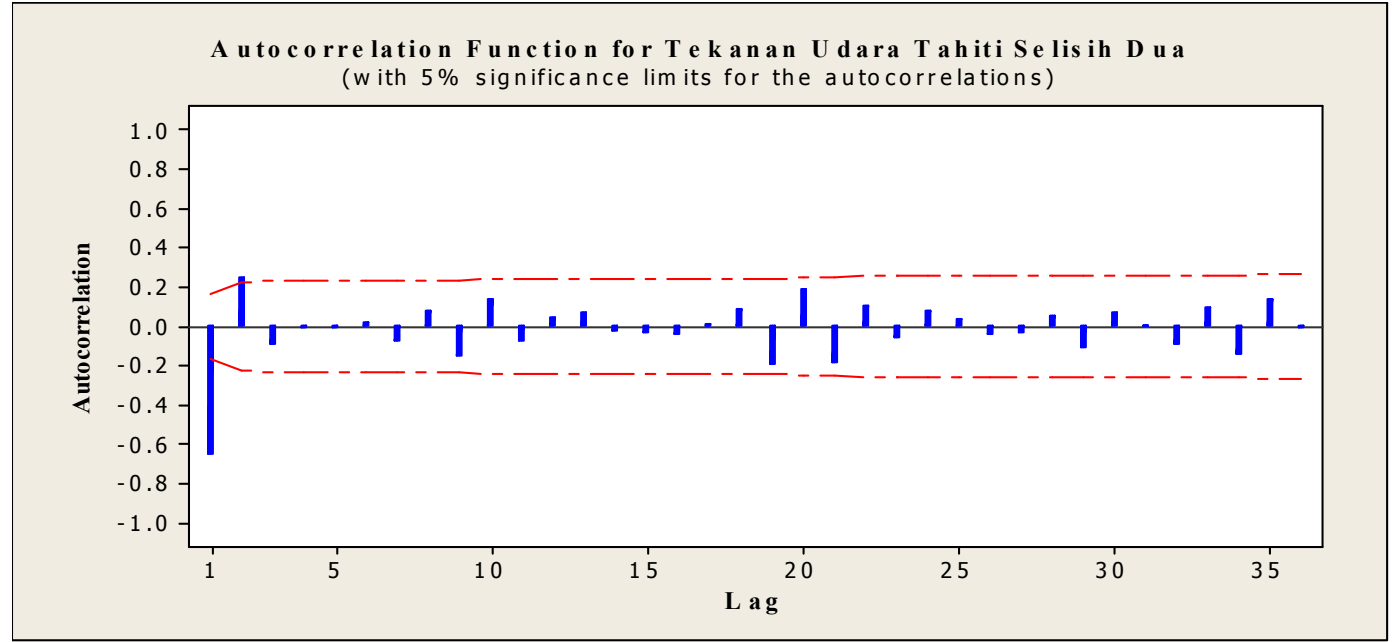

Gambar 4.3. Pola ACF Tekanan Udara Tahiti Selisih Dua 


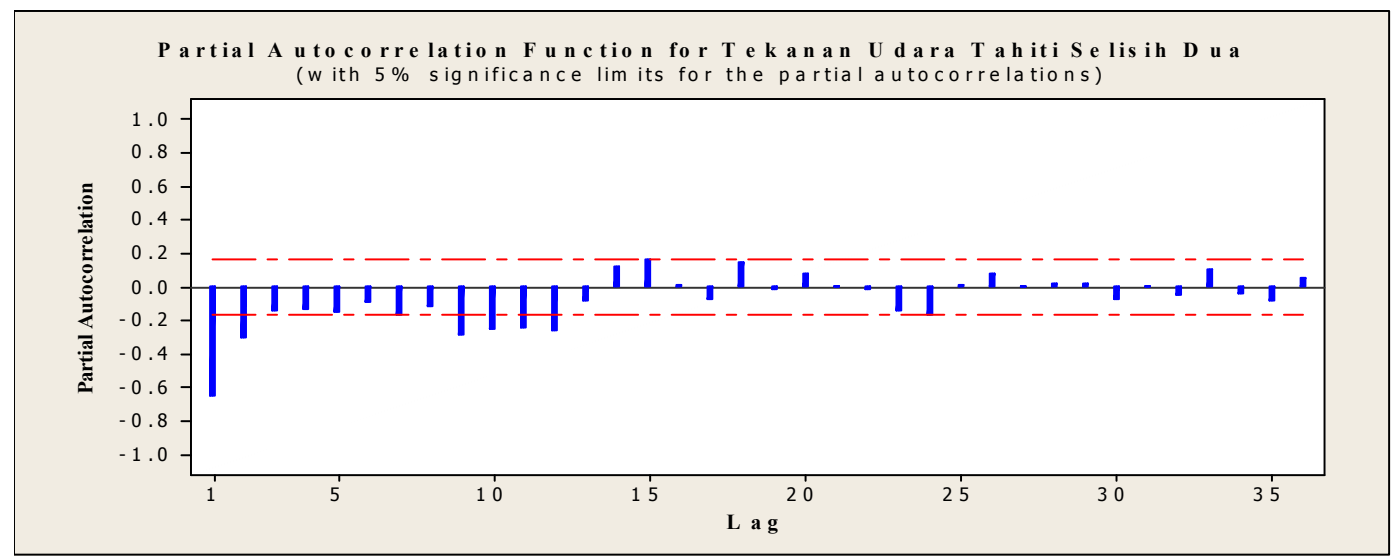

Gambar 4.4. Pola PACF Tekanan Udara Tahiti Selisih Dua

Setelah dilakukan difference sebanyak dua kali, data sudah menunjukkan stasioner. Ini dapat dilihat dari Gambar 4.2, bahwa data senantiasa mengikuti rata-ratanya pada garis linier tersebut. Oleh karena data sudah stasioner maka sudah dapat dilakukan identifikasi sementara untuk tekanan udara Tahiti berdasarkan grafik ACF dan PACF.

\subsubsection{Tekanan Udara Darwin}

Setelah melihat kestasioneran data tekanan udara Tahiti, maka selanjutnya dilakukan hal yang sama untuk data tekanan udara Darwin.

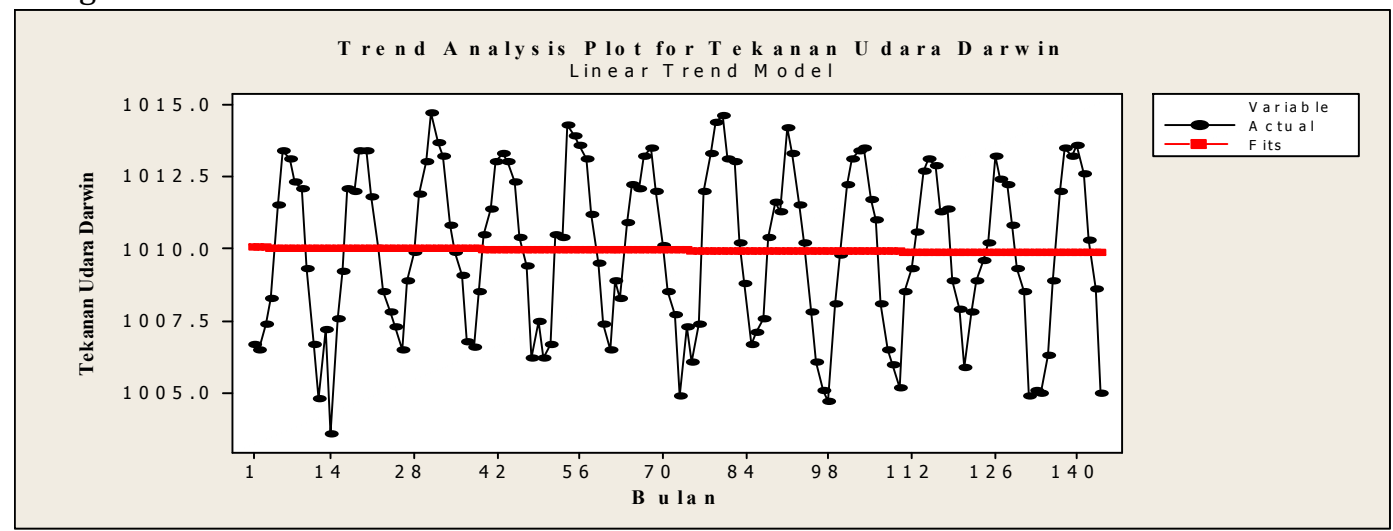

Gambar 4.5 Pola Trend analisis Tekanan Udara Darwin 144 Bulan

Berdasarkan Gambar 4.5 grafik trend menunjukkan bahwa data tersebut belum stasioner. Ini dikarenakan data tersebut senantiasa tidak berada dalam rata-ratanya. garis merah menunjukkan garis linier nilai rata- rata dari data tersebut. Akan tetapi, banyaknya data yang berada jauh diatas dan dibawah nilai rata-rata, sehingga dikatakan bahwa data tersebut belum stasioner. sehingga harus dilakukan difference agar data stasioner.

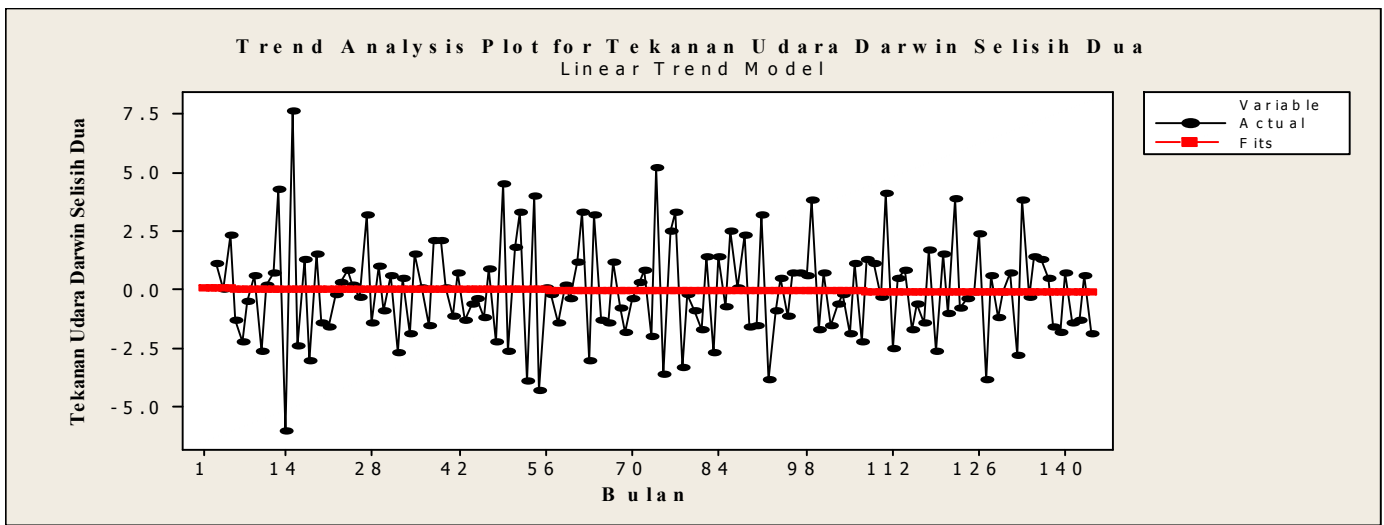

Gambar 4.6 Pola Trend Analisis Tekanan Udara Darwin Differencing Dua Kali 
Pada Gambar 4.6 adalah grafik yang menunjukkan kestasioneran dari data tekanan udara Darwin setelah dilakukan difference sebanyak dua kali. Dari gambar tersebut terlihat bahwa data sudah dapat dikatakan stasioner terhadap nilai rata-ratanya, walaupun masih ada beberapa data yang terlihat berada jauh dari rata-rata. Akan tetapi, sudah dapat dilakukan identifikasi model sementara dari grafik ACF dan PACF berikut ini.

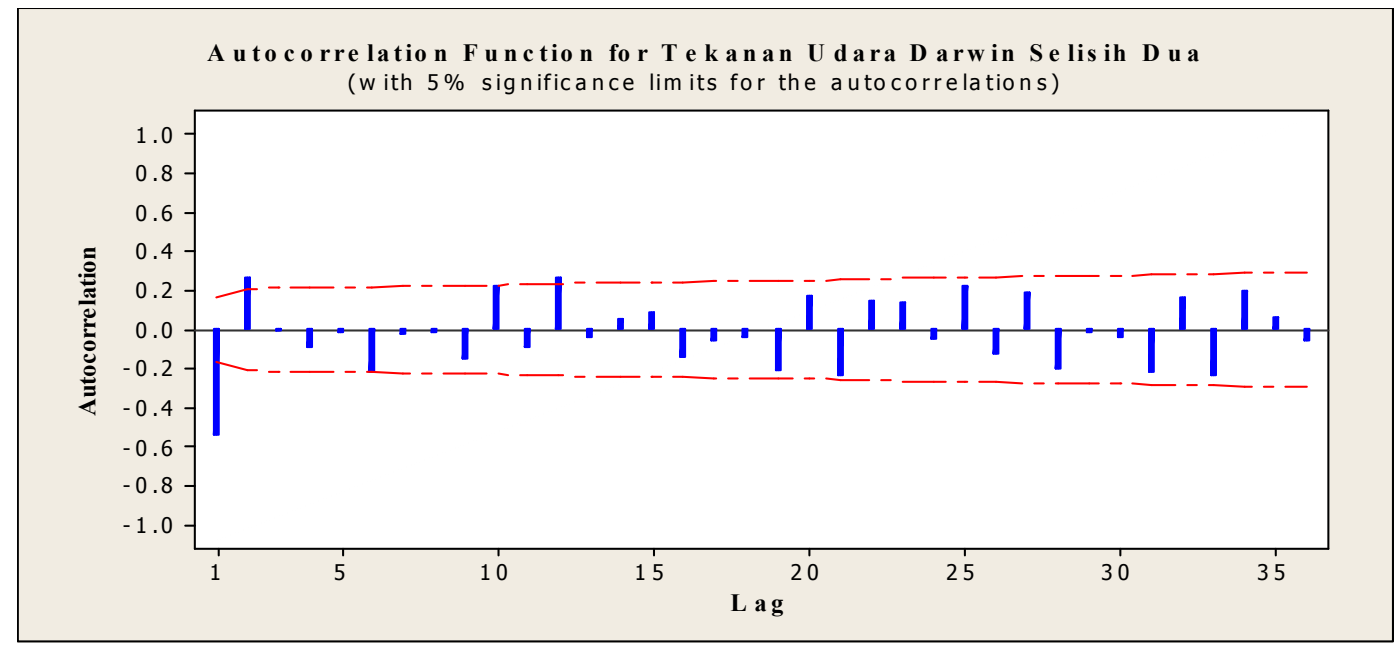

Gambar 4.7 Pola ACF Tekanan Udara Darwin Selisih Kedua

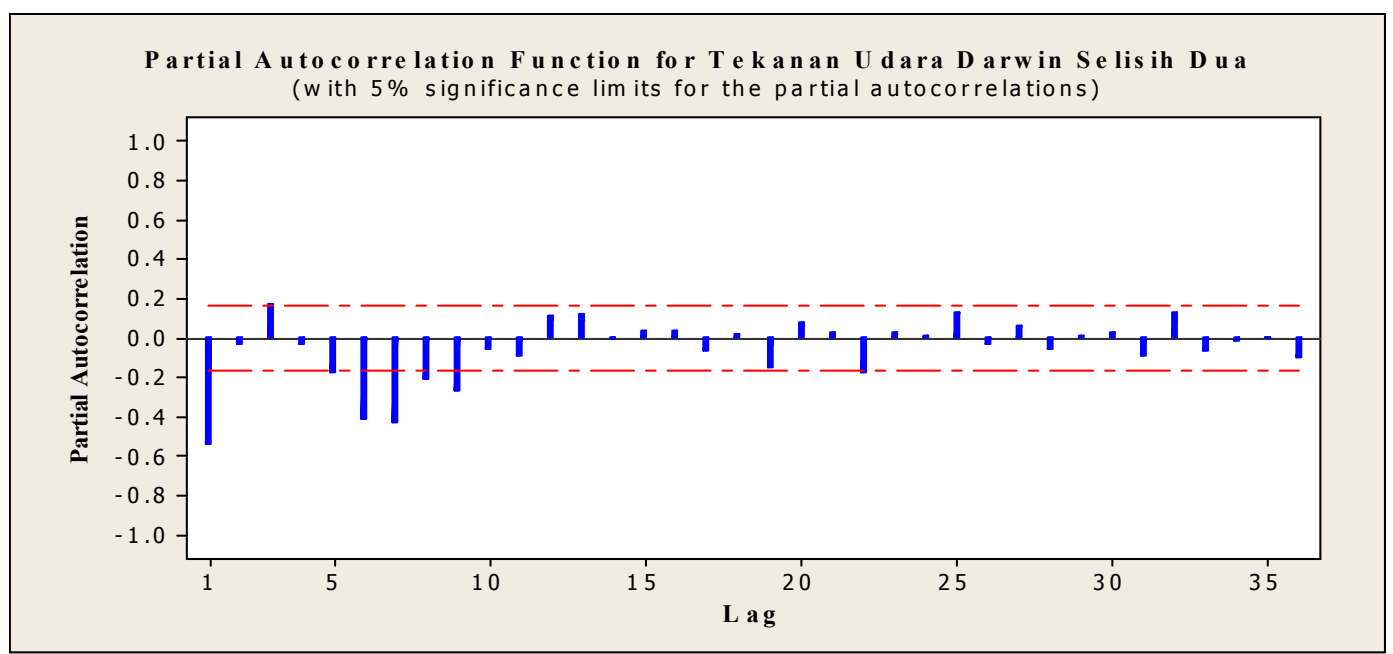

Gambar 4.8 Grafik PACF Tekanan Udara Darwin Selisih Kedua

\subsection{Identifikasi Model Sementara}

Proses identifikasi model ARIMA (p,d,q) dapat dilakukan dengan mengenal ciri-ciri ACF dan PACF suatu model. Jika ciri-ciri ACF dan PACF dapat dikenali maka dapat ditentukan model dari data yang stasioner.

Untuk menentukan orde $\mathrm{p}$ dan $\mathrm{q}$ bisa diidentifikasi dari grafik ACF dan PACF pada data yang sudah stasioner. Nilai $\mathrm{p}$ ditentukan dengan melihat pada time lag berapa terdapat garis yang keluar batas pada grafik fungsi PACF. Orde $\mathrm{p}$ bernilai 1 ditandai dengan adanya satu garis yang keluar batas pada lag pertama. Orde $\mathrm{p}$ bernilai 2 ditandai dengan adanya dua garis yang keluar batas pada lag pertama dan kedua. Nilai q ditentukan dengan melihat pada time lag terdapat garis yang keluar batas signifikansi. Berdasarkan pertimbangan diatas maka model berapa terdapat garis yang keluar batas pada grafik fungsi ACF. Jika terdapat satu garis keluar pada lag1, maka orde q bernilai 1 , tetapi jika terdapat dua garis keluar pada lag1 dan 2, maka orde q bernilai 2 .

Hasil dari grafik PACF Gambar 4.4 menunjukkan bahwa pada time lag pertama dan kedua terdapat garis yang keluar batas, sehingga orde $\mathrm{p}$ bernilai 2 dan grafik ACF Gambar 4.3 menunjukkan pada time lag pertama dan kedua terdapat garis yang keluar batas, sehingga orde $\mathrm{q}$ bernilai 2 . Oleh karena data memiliki periode musiman 12 bulan maka terdapat orde $(P, D, Q)^{S}$ pada model ini. Pada gambar 4.8 grafik PACF tekanan udara Darwin menunjukkan orde $\mathrm{P}$ bernilai 1 karena pada lag pertama 
sementara untuk prediksi tekanan udara Tahiti $(2,2,2)(2,2,2)^{12}$ dan tekanan udara Darwin adalah $(1,2,2)(1,2,2)^{12}$.

\subsection{Estimasi Model Sementara \\ 4.3.1 Tekanan Udara Tahiti}

Untuk melihat model ARIMA terbaik dari hasil estimasi parameter model sementara, maka dilakukan pengujian tingkat korelasi antara nilai tekanan udara di Tahiti observasi dengan nilai tekanan udara hasil estimasi. Dari hasil tersebut, tedapat beberapa model yang memiliki nilai korelasi yang baik diatas 0,6 untuk tekanan udara Tahiti yaitu model ARIMA $(0,2,2)(0,2,2)^{12}$,

$(1,2,0)(0,2,2)^{12},(1,2,2)(1,2,2)^{12},(2,2,0)(0,2,2)^{12}$

dengan nilai korelasi masing-masing sebesar 0,7864; 0,7508; 0,7409; dan 0,7845. Berdasarkan keempat model tersebut model ARIMA $(1,2,0)(0,2,2)^{12}$ dianggap sebagai model yang bagus untuk prediksi tekanan udara Tahiti berikutnya, walaupun model ini bukan merupakan model yang memiliki korelasi tertinggi dari keempat model tersebut. Grafik korelasi untuk model $(1,2,0)(0,2,2)^{12}$ dapat dilihat pada gambar dibawah ini.

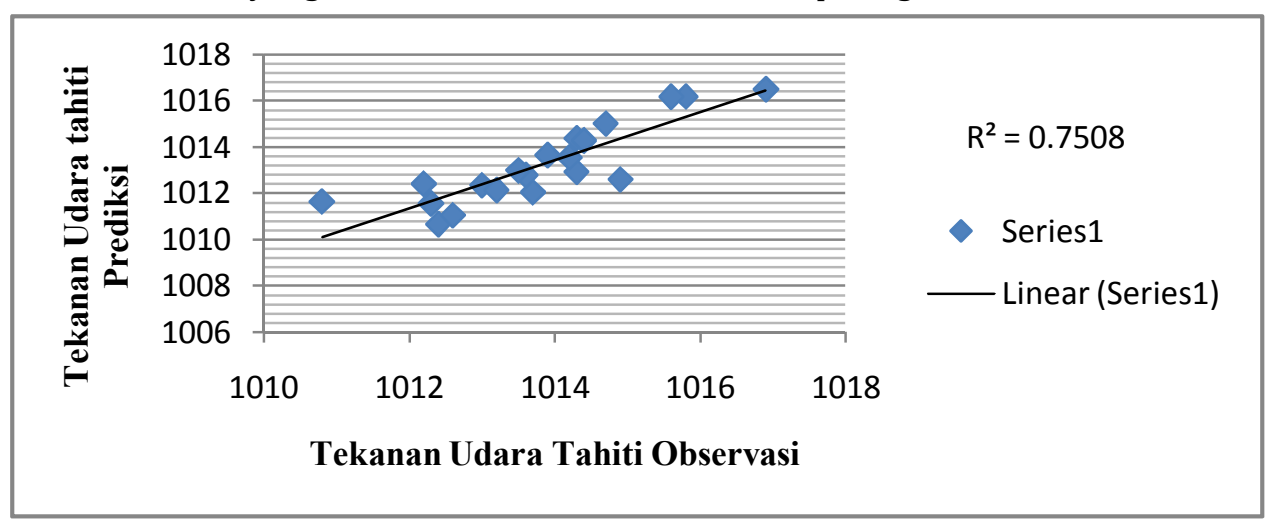

Gambar 4.9 Grafik tingkat Korelasi Tekanan Udara Tahiti Observasi dengan Hasil Estimasi Model ARIMA $(1,2,0)(0,2,2)^{12}$

Adapun persamaan yang digunakan dalam melakukan prediksi tekanan udara Tahiti dari model $(1,2,0)(0,2,2)^{12}$ adalah sebagai berikut :

$(1-\theta B)(1-B)\left(1-B^{12}\right) Y t=(1-W B)^{12} \varepsilon_{t}$

dengan :

AR (Tidak Musiman) $\quad:(1-\theta B)$

$: \theta=-0.7068$

I (Pembeda Musiman) : $\left(1-B^{12}\right)$

I (Pembeda Tidak Musiman): $(1-B)$

MA (Musiman) $\quad:(1-W B)^{12}$

: $W=-0.7171$
Sehingga diperoleh persamaan model ARIMA yang sesuai untuk memprediksi nilai tekanan udara Tahiti adalah

$$
\begin{aligned}
Y t= & 0.2932 Y_{t-1}-0.7068 Y_{t-2}-Y_{t-12}+ \\
& 0.2932 Y_{t-13}+0.7068 Y_{t-14}+1.7171 Y_{t-12} \varepsilon_{t}
\end{aligned}
$$

\subsubsection{Tekanan Udara Darwin}

Pada tekanan udara Darwin terdapat 34 model yang menunjukkan korelasi yang baik. Dari 34 model yang dianggap paling cocok untuk prediksi tekanan udara Darwin adalah model ARIMA $(1,2,2)(0,2,1)^{12}$ dengan korelasi sebesar 0,996 seperti yang ditunjukkan pada gambar berikut.

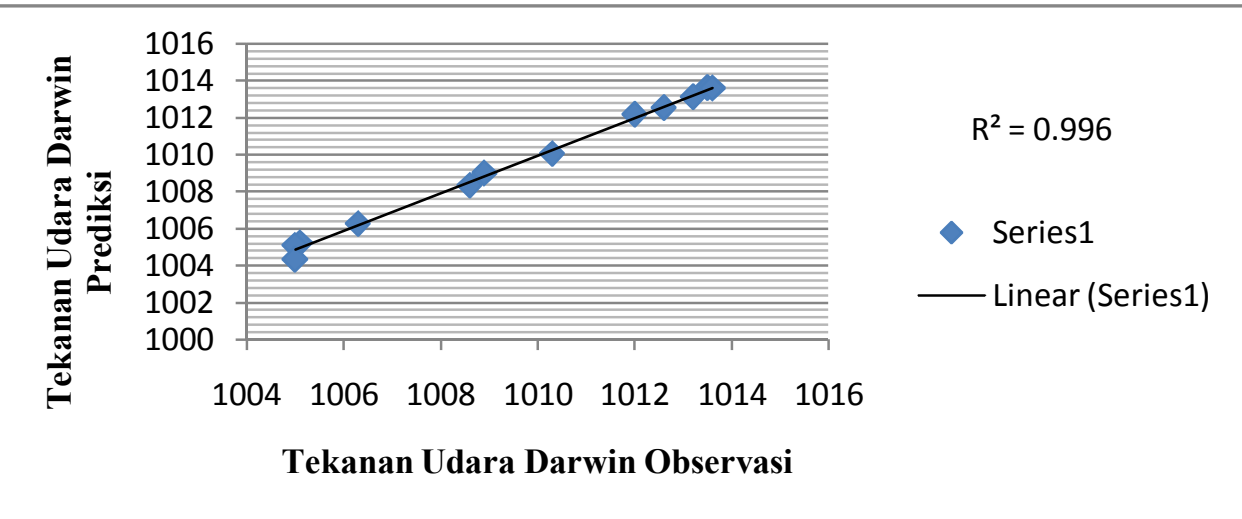

Gambar 4.10. Grafik Korelasi Tekanan Udara Darwin dengan Hasil Estimasi Model ARIMA $(1,2,2)(0,2,1)^{12}$ 
Persamaan yang digunakan dalam melakukan prediksi tekanan udara Darwin dari model $(1,2,2)(0,2,1)^{12}$ adalah sebagai berikut : $(1-\theta B)(1-B)\left(1-B^{12}\right) Y t=(1-W B)^{12} \varepsilon_{t}$

dengan :

AR (Tidak Musiman) $\quad:(1-\theta B)$

$$
: \theta=-0.3447
$$

I (Pembeda Musiman) $\quad:\left(1-B^{12}\right)$

I (Pembeda Tidak Musiman): $(1-B)$

MA (Tidak Musiman) $\quad:(1-W B)$

MA (Musiman)

$: W=-0.2428$

$:(1-W B)^{12}$

: $W=0.8419$

Sehingga diperoleh persamaan model ARIMA yang sesuai untuk memprediksi nilai tekanan udara Darwin adalah :

$$
\begin{aligned}
Y t= & 0.6553 Y_{t-1}+0.3447 Y_{t-2}-Y_{t-12}- \\
& 0.6553 Y_{t-13}-0.3447 Y_{t-14}+1.2428 Y_{t-1}+ \\
& 0.1581 Y_{t-12} \varepsilon_{t}
\end{aligned}
$$

\subsection{Prediksi SOI Model ARIMA}

Berdasarkan hasil korelasi model ARIMA tekanan udara Tahiti $(1,2,0)(0,2,2)^{12}$ dan tekanan udara Darwin $(1,2,2)(0,2,1)^{12}$ terlihat bahwa model dinilai cukup akurat untuk prediksi. Hal ini, dapat diperjelas pada tabel berikut ini.

Tabel 4.1 Prediksi Tekanan Udara Tahiti dan Darwin dengan Model ARIMA $(1,2,0)(0,2,2)^{12}$ dan $(1,2,2)(0,2,1)^{12}$ Tahun 2011.

\begin{tabular}{cccc}
\hline \multirow{2}{*}{ Tahun/Bulan } & \multicolumn{2}{c}{2011} & \multirow{2}{*}{ SOI } \\
\cline { 2 - 3 } & $\begin{array}{c}\text { Tahiti } \\
(\mathrm{mb})\end{array}$ & $\begin{array}{c}\text { Darwin } \\
(\mathrm{mb})\end{array}$ & \\
\hline Januari & 1012.05 & 1005.23 & 11,5 \\
Februari & 1012.92 & 1005.09 & 15,4
\end{tabular}

\begin{tabular}{cccc} 
Maret & 1013.55 & 1006.27 & 18,2 \\
April & 1014.38 & 1009 & 24,8 \\
Mei & 1013.65 & 1012.17 & $-0,9$ \\
Juni & 1015.01 & 1013.61 & 1,7 \\
Juli & 1016.18 & 1013.12 & 13,7 \\
Agustus & 1016.17 & 1013.59 & 5,5 \\
September & 1016.49 & 1012.54 & 9,1 \\
Oktober & 1014.28 & 1010.05 & 8,3 \\
November & 1012.79 & 1008.34 & 10,3 \\
Desember & 1012.35 & 1004.35 & 22,5 \\
\hline
\end{tabular}

Tabel 4.2 Prediksi Tekanan Udara Tahiti dan Darwin dengan Model ARIMA $(1,2,0)(0,2,2)^{12}$ dan $(1,2,2)(0,2,1)^{12}$ Tahun 2012.

\begin{tabular}{cccc}
\hline \multirow{2}{*}{ Tahun/Bulan } & \multicolumn{2}{c}{2012} & \\
\cline { 2 - 3 } & $\begin{array}{c}\text { Tahiti } \\
(\mathrm{mb})\end{array}$ & $\begin{array}{c}\text { Darwin } \\
(\mathrm{mb})\end{array}$ & SOI \\
\hline Januari & 1010.67 & 1004.55 & 8,2 \\
Februari & 1011.56 & 1004.3 & 12,7 \\
Maret & 1011.65 & 1005.29 & 13,1 \\
April & 1012.41 & 1008.07 & 16,2 \\
Mei & 1011.05 & 1011.25 & $-13,8$ \\
Juni & 1012.14 & 1012.56 & $-13,5$ \\
Juli & 1012.99 & 1011.81 & 1,2 \\
Agustus & 1012.6 & 1012.28 & $-8,6$ \\
September & 1012.57 & 1011.1 & $-5,5$ \\
Oktober & 1009.74 & 1008.35 & $-9,4$ \\
November & 1007.93 & 1006.56 & $-10,2$ \\
Desember & 1007.12 & 1002.12 & 7,5 \\
\hline
\end{tabular}

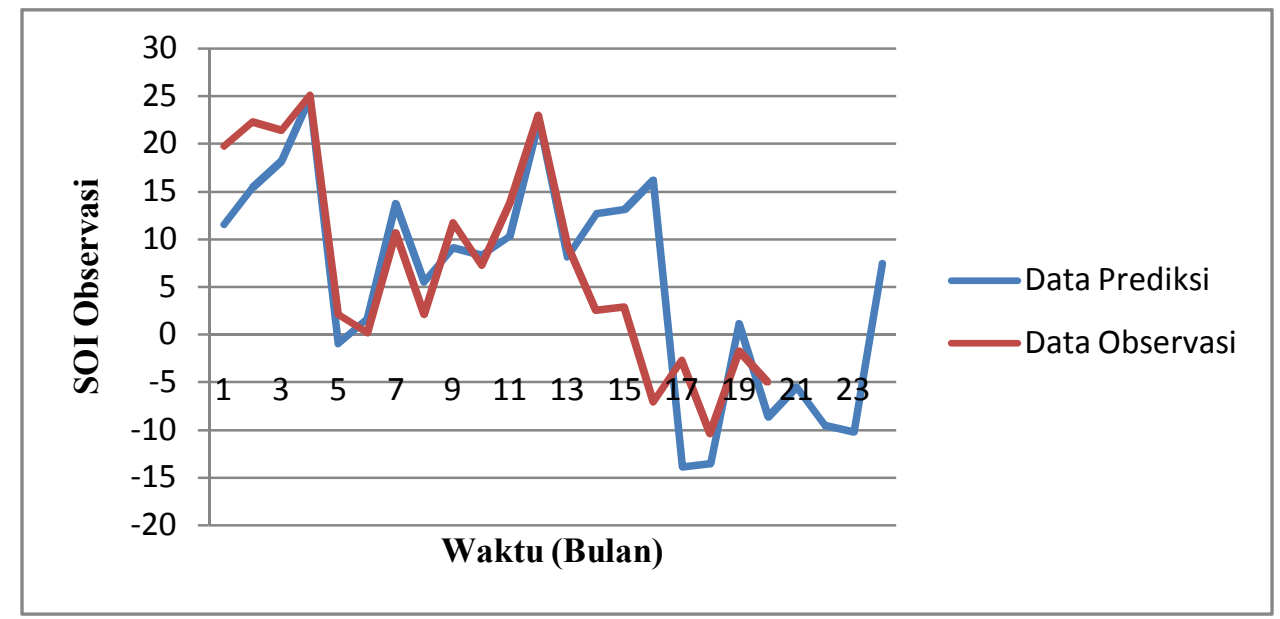

Gambar 4.11. Grafik SOI Berdasarkan observasi dan hasil Prediksi Tahun 2011-2012

\subsection{Analisis Hasil Prediksi}

Setelah melihat hasil prediksi antara keduanya maka selanjutnya nilai SOI yang diperoleh pada tahun 2012 masing-masing adalah 8,$2 ; 12,7 ; 13,1 ; 16,2 ;-13,8 ;-13,5 ; 1.2 ;-$ 8,6; -5,5; -9,4; -10,2; dan 7,5. Oleh karena itu, dapat dikatakan bahwa pada tahun 2012 akan terjadi fenomena alam El-Nino lemah sampai 
sedang karena pada bulan Juni dan Agustus memiliki nilai SOI dibawah -10 dan ini diikuti hingga bulan November. Sehingga dapat diprediksikan akan terjadi bencana alam kekeringan pada tahun 2012 karena penurunan curah hujan. Hasil ini dapat dilihat berdasarkan gambar dibawah ini dengan tingkat korelasi sebesar 0,5713.

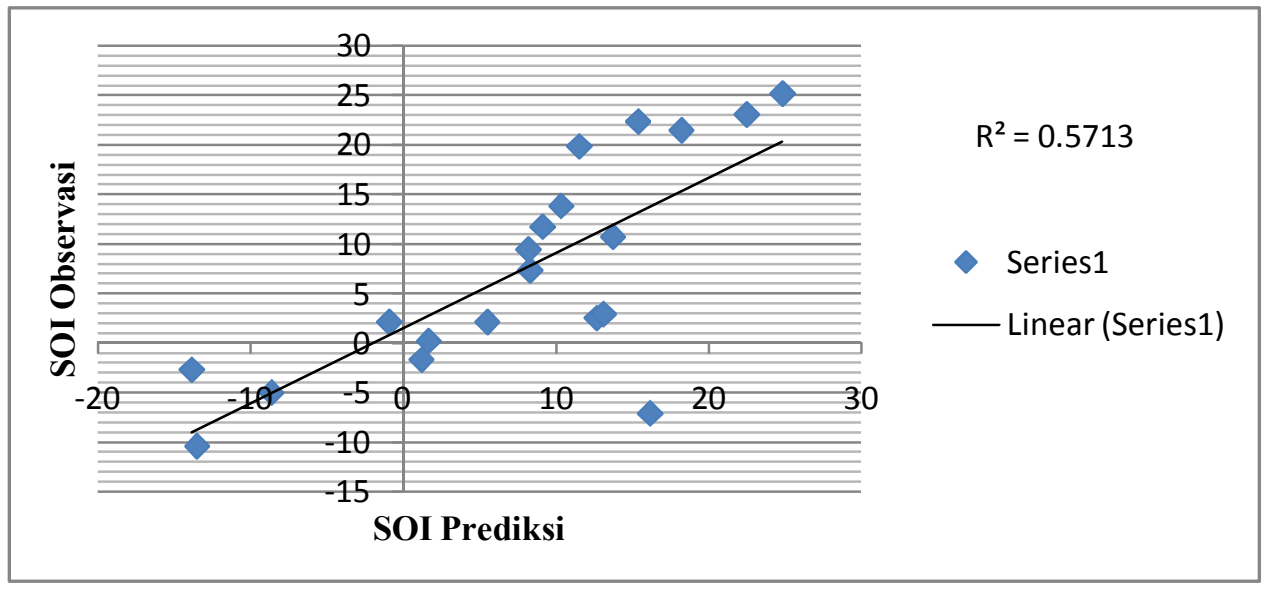

Gambar 4.12. Grafik Tingkat Korelasi SOI Berdasarkan observasi dan hasil Prediksi Tahun 2011-2012

\section{Kesimpulan}

Berdasarkan penelitian yang telah dilakukan, maka dapat disimpulkan sebagai berikut :

1. Model ARIMA untuk prediksi nilai tekanan udara Tahiti dan Darwin yang terbaik adalah ARIMA $(1,2,0)(0,2,2)^{12}$ dengan korelasi sebesar 0,7508 dan model ARIMA $(1,2,2)(0,2,1)^{12}$ dengan korelasi 0,996 .

2. Berdasarkan hasil prediksi tekanan udara Tahiti dan Darwin maka dapat dikaji bahwa akan terjadi fenomena alam El-Nino lemah sampai sedang pada tahun 2012.

\section{Pustaka}

Edukasi, 2010, La-Nina, http://www.edukasi.net/index. php?mod= script\&cmd = Bahan \% 20 Belajar /Pengetahuan \% 20Populer / view\&id=67\&uniq=all. Akses tanggal 29 Februari 2012.

Gunawan, D., 2007, Cuaca dan Iklim Indonesia, http:// www. dirgantara-lapan. or. id/ moklim/

download/lecturer/Cuaca\%20dn\%20Ik lim.pdf. Akses tanggal 29 Februari 2012.

Haryanto, U., 1998, Keterkaitan Fase SOI Terhadap Curah Hujan Di DAS Citarum, http://repository. ipb.ac.id/ bitstream/handle/ 123456789/ 4016/ 1998 uha.pdf?sequence=. Akses tanggal 29 Februari 2012.

Makridakis, S., Steven C. Wheelwright., Victor E. McGee., 1999, Metode Aplikasi dan peramalan, Erlangga, Jakarta.
Murtianto, H., 2012, ENSO (El-Nino Southern Oscilation), http:// file.upi. edu /Direktori /FPIPS /Lainnya/ Hendro_Murtianto /05_ENSO.pdf.Akses tanggal 29 Februari 2012. 